\title{
Avaliação múltipla em bacias hidrográficas de grande escala
}

\author{
Multiple assessment in large-scale river basins \\ Evaluación múltiple en cuencas hidrográficas a gran escala
}

Recebido: 13/01/2022 | Revisado: 19/01/2022 | Aceito: 29/01/2022 | Publicado: 30/01/2022

\author{
Jhony Ferry Mendonça da Silva \\ ORCID: https://orcid.org/0000-0001-9932-2963 \\ Universidade Estadual do Oeste do Paraná, Brasil \\ E-mail: jhonyferry@ hotmail.com \\ Elaine Fernandes Celestino \\ ORCID: https://orcid.org/0000-0002-5485-6440 \\ Universidade Estadual do Oeste do Paraná, Brasil \\ E-mail: layne_fernandes@ hotmail.com \\ Guilherme Henrique Barros de Souza \\ ORCID: https://orcid.org/0000-0001-9137-171X \\ Universidade Estadual Paulista Júlio de Mesquita Filho, Brasil \\ E-mail: guilherme.barros@unesp.br \\ Max Portuguez Obeso \\ ORCID: https://orcid.org/0000-0001-5248-4850 \\ Universidade Estadual do Oeste do Paraná, Brasil \\ Instituto Federal de Educação Ciência e Tecnologia do Tocantins, Brasil \\ E-mail: maxobeso@ifto.edu.br \\ Maristela Cavicchioli Makrakis \\ ORCID: https://orcid.org/0000-0001-7539-9659 \\ Universidade Estadual do Oeste do Paraná, Brasil \\ E-mail: Maristela.Makrakis@unioeste.br \\ Sergio Makrakis \\ ORCID: https://orcid.org/0000-0002-7868-9034 \\ Universidade Estadual do Oeste do Paraná, Brasil \\ E-mail: sergio.makrakis@unioeste.br
}

\begin{abstract}
Resumo
O conhecimento da morfometria, do relevo e rede de drenagem bacias hidrográficas é importante para a gestão ambiental. Portanto, este estudo visa caracterizar a morfometria e identificar as características do relevo em nove bacias hidrográficas afluentes do rio Iguaçu. A caracterização de vertentes, rede de drenagem e declividade foi realizada utilizando um Modelo Digital de Terreno (MDT) e os dados obtidos foram comparados visualmente aos resultados das cartas topográficas da Agência Nacional de Águas (ANA) (2015). As bacias analisadas apresentaram de maneira geral formas alongadas, sendo pouco suscetíveis à enchentes, com relevo ondulado, possuem drenagem intermediária a pobre e sinuosidade de intermediária a alta. Os resultados obtidos se assemelham aos obtidos pela ANA (2015), baseados em escalas menores. As hierarquias para cada bacia foram satisfatórias, assim como a metodologia utilizada, pois não requer a utilização de máquinas sofisticadas para a sua execução, e resulta em dados confiáveis com pouca perda de precisão. Os resultados são inéditos para essas bacias e as variáveis geomorfológicas estimadas podem apoiar a tomada de decisão tanto em relação aos riscos das atividades antrópicas quanto para a definição de áreas de conservação, especialmente de áreas de interesse para a conservação da água e dos ecossistemas aquáticos.
\end{abstract}

Palavras-chave: Geomorfologia; Declividade; Geoprocessamento; Projetos ambientais.

\begin{abstract}
The knowledge of morphometry, relief and drainage network of hydrographic basins is important for environmental management. Therefore, this study aims to characterize the morphometry and identify the relief characteristics in nine hydrographic basins tributary of the Iguaçu River. The characterization of slopes, drainage network and slope was performed using a Digital Terrain Model (DTM) and the data obtained were visually compared to the results of the topographic maps of the National Water Agency (ANA) (2015). The analyzed basins presented in general elongated shapes, being little susceptible to floods, with undulating relief, with intermediate to poor drainage and sinuosity from intermediate to high. The results obtained are similar to those obtained by ANA (2015), based on smaller scales. The hierarchies for each basin were satisfactory, as well as the methodology used, as it does not require the use of sophisticated machines for its execution, and results in reliable data with little loss of precision. The results are unprecedented for these basins and the estimated geomorphological variables can support decision making both in
\end{abstract}


relation to the risks of anthropic activities and the definition of conservation areas, especially areas of interest for the conservation of water and aquatic ecosystems.

Keywords: Geomorphology; Slope; Geoprocessing; Environmental projects.

\section{Resumen}

El conocimiento de la morfometría, relieve y redes de drenaje de las cuencas hidrograficas es importante para la gestión ambiental. Por tanto, este estudio tiene como objetivo caracterizar la morfometría e identificar las características del relieve en nueve cuencas tributarias del río Iguazú. La caracterización de taludes, red de drenaje y talud se realizó mediante un Modelo Digital de Terreno (DTM) y los datos obtenidos se compararon visualmente con los resultados de los mapas topográficos de la Agencia Nacional del Agua (ANA) (2015). Las cuencas analizadas se presentaron en formas generalmente alargadas, siendo poco susceptibles a inundaciones, con relieve ondulado, con drenaje intermedio a pobre y sinuosidad de intermedio a alto. Los resultados obtenidos son similares a los obtenidos por ANA (2015), basados en escalas menores. Las jerarquías para cada cuenca fueron satisfactorias, así como la metodología utilizada, ya que no requiere el uso de máquinas sofisticadas para su ejecución, y da como resultado datos confiables con poca pérdida de precisión. Los resultados son inéditos para estas cuencas y las variables geomorfológicas estimadas pueden apoyar la toma de decisiones tanto en relación a los riesgos de las actividades antrópicas como en la definición de áreas de conservación, especialmente áreas de interés para la conservación de agua y ecosistemas acuáticos.

Palabras clave: Geomorfología; Pendiente; Geoprocesamiento; Proyectos ambientales.

\section{Introdução}

A exploração dos recursos naturais, a exemplo da silvicultura, agricultura, canalização, produção de energia elétrica, industrialização e muitas outras atividades, têm consequências diversas para o meio ambiente. Algumas dessas intervenções aceleram processos geomorfológicos que demorariam milhares de anos (Guerra \& Cunha, 1999), modificam os ecossistemas aquáticos e impactam diretamente suas comunidades (Roni et al., 2005; Tundisi, 2005, pp. 59-66). Assim, o conhecimento da morfometria, do relevo e da rede de drenagem são fundamentais para o planejamento e gestão em projetos ambientais, e a sua obtenção segue sendo um desafio. As mudanças espaço-temporais da superfície terrestre podem ser compreendidas por meio das alterações nas bacias hidrográficas. Definidas como uma área onde a água converge para um único ponto em uma elevação mais baixa, normalmente a seu exutório (Rahaman et al., 2015). As bacias são, também, a unidade territorial de gestão de recursos hídricos (Lei n. 9.433, 1997).

As características morfológicas das bacias hidrográficas são controladas ou influenciadas por sua estrutura geológica (Tonello et al., 2006) e litologia (Nickolas et al., 2017), atuantes nos processos do ciclo hidrológico influenciando a infiltração, a água produzida como deflúvio da precipitação, dos escoamentos superficial e subsuperficial, evaporação e formação dos elementos que compõem a superfície terrestre (Lorandi \& Cançado, 2002; Pissarra et al., 2004). Do mesmo modo, as condições de umidade do solo, mecanismos de geração de escoamento subterrâneo, potencial de água subterrânea e processos relacionados ao fluxo subterrâneo (Lima, 2008). O sistema de drenagem, influenciado pela forma do relevo, regime climático, hidrológico, formações geológicas, morfológicas, solos, vegetação, entre outros (Grison \& Kobiyama, 2011). Assim, a área da bacia hidrográfica influencia a quantidade de água produzida como deflúvio e a extensão dos canais, afetando a disponibilidade de sedimentos e a taxa de formação do deflúvio (Santos et al., 2012). Por outro lado, a forma e o relevo, atuam sobre a taxa de produção de água e de sedimentação (Tonello, 2006).

A caracterização morfométrica é um dos métodos para o planejamento e manejo de bacias contribui para o entendimento do padrão de drenagem, e avaliação comparativa de drenagens desenvolvidas em vários sistemas geológicos e climáticos (Pingale Chandra et al., 2012). A caracterização de bacia implica no entendimento das suas formações geomorfológicas, que são dependentes da relação entre a precipitação, infiltração e o deflúvio (Pissarra et al., 2004). O rompimento do equilíbrio entre infiltração e escoamento superficial do ecossistema terrestre, influencia diretamente no ecossistema aquático (Reis \& Pereira Filho, 2006. A hierarquia fluvial torna os estudos morfométricos mais objetivos. Por 
meio da análise dos canais e suas formas pode-se definir o padrão de drenagem, que repercute no comportamento hidrológico e litológico de cada unidade de solo (Christofoletti, 1980). Nessa condição, estudos ambientais de demanda hídrica são essenciais para determinar o uso racional dos recursos hídricos (Carvalho et al., 2021), e na avaliação da condição das bacias hidrográficas (Ahn \& Kim, 2019).

No estudo de variáveis de morfometria, o uso da tecnologia geoespacial possui vantagens pela disponibilidade espacial, espectral, temporal e de manipulação de dados cobrindo áreas grandes, às vezes inacessíveis num período curto (Dar, Sankar, \& Dar, 2010). Com essas tecnologias é possível obter variáveis de relevo, rede de drenagem e declividade (Miguel et al., 2014). A extensão e a forma da bacia estão relacionadas com a quantidade de água que ela pode captar (Fioreze, Oliveira, \& Franco, 2010). Enquanto o relevo e a densidade de drenagem afetam a velocidade de escoamento e capacidade de absorção de água pelo solo (Tucci, 2001). As informações de relevo são representadas por uma estrutura numérica de dados correspondente à distribuição espacial da altitude e da superfície do terreno, denominada Modelo Digital de Terreno (MDT) (Oliveira et al., 2010).

O MDT possui uma gama de fatores topográficos na modelagem do terreno, permitindo que várias características quantitativas de relevo e interpretações analíticas sejam obtidas (Rahmati et al., 2018). São utilizados para automatizar a geração de direções de fluxo, redes de drenagem e bacias hidrográficas (Freitas, Freitas, Rosim, \& Oliveira, 2016). Podem ser obtidos por meio da interpolação de curvas de nível extraídas de uma carta topográfica, ou através de imagens de sensores remotos (Oliveira et al., 2010). Com o MDT, é possível obter variáveis físicas e geomorfológicas em bacias, auxiliando no planejamento, na tomada de decisões, na aplicação da legislação ambiental, na avaliação dos efeitos das ações antrópicas (Mioto et al., 2014, Pissarra et al., 2004, Tonello et al., 2006, Lima, 2008, Rahmati et al., 2018).

Desta forma, este estudo caracterizou nove bacias hidrográficas do Baixo Rio Iguaçu quanto à sua morfometria, relevo e rede de drenagem utilizando o Modelo Digital de Terreno (MDT) e comparou com as bases cartográficas da região para verificar a precisão dos dados. Essas informações inferem sobre a qualidade do ambiente e para a conservação dos recursos pesqueiros na região, podendo auxiliar na tomada de decisões com relação ao manejo desses ambientes.

\section{Metodologia}

\section{Área de Estudo}

A área de estudo está localizada na divisa entre o estado do Paraná, no Brasil e o estado de Missiones, na Argentina. Possui clima subtropical úmido com verões quentes e úmidos e invernos moderados (Köppen \& Geiger, 1936). A região do Baixo Rio Iguaçu, possui clima subtropical com temperatura média no mês mais frio abaixo de $18^{\circ} \mathrm{C}$, e temperatura média no mês mais quente acima de $22^{\circ} \mathrm{C}$ (Nitsche et al., 2019).

A área estudada corresponde a nove (9) bacias de rios afluentes do Baixo Rio Iguaçu. Está localizada a jusante da usina hidrelétrica de Salto Caxias e os tributários são contribuintes para a vazão das Cataratas do Iguaçu. Na margem direita estão os rios Andrada, Monteiro, Gonçalves Dias, Floriano e Silva Jardim e na margem esquerda os rios Cotejipe, Sarandi, Capanema e Santo Antônio. Com área aproximada de 482.600 ha, essas bacias fazem parte dos municípios de Âmpere, Bela Vista da Caroba, Capanema, Capitão Leônidas Marques, Céu Azul, Matelândia, Nova Prata do Iguaçu, Pérola d'Oeste, Planalto, Realeza, Santa Izabel do Oeste, Santa Lúcia, Santa Tereza do Oeste, Serranópolis do Iguaçu e Lindoeste (Figura 1).

As bacias dos rios Floriano, Silva Jardim e Gonçalves Dias estão, total ou parcialmente, inseridas na área do Parque Nacional do Iguaçu (PNI). A bacia do rio Floriano tem $713 \mathrm{~km}^{2}$ e está totalmente protegida, com seus limites na zona intangível da Unidade de Conservação o que garante sua integridade, assim é referência em padrões hidrológicos. O PNI é uma Unidade de Proteção Integral (185.262,5 ha), foi criada pelo Decreto Federal nº. 1035, de 10 de janeiro de 1939 e teve seus 
limites alterado pelo Decreto $\mathrm{n}^{\circ} 86.676$ de 01 de dezembro de 1981. A área preserva um remanescente florestal importante de Mata Atlântica (Instituto Chico Mendes de Conservação da Biodiversidade [ICMBio], 2018).

O solo da região é ocupado principalmente pela agricultura, pastagem e centros urbanos (Celestino et al., 2019).

\section{Procedimentos para obtenção e análise de dados}

Esta pesquisa de natureza descritiva e abordagem quali-quantitativa buscou informações para a caracterização da morfometria, relevo e rede de drenagem de nove bacias hidrográficas do Baixo Rio Iguaçu tendo como base os autores Strahler (1952), Christofoletti (1980), Oliveira et al. (2010) e Schumm (1956) dentre outros. Os procedimentos técnicos encontram-se descritos a seguir.

As informações foram obtidas e analisadas utilizando o Sistema de Informações Geográficas (SIG) QGIS versão 2.8 Wien, com os complementos Terrain Analysis Using Digital Elevation Models (TauDEM) versão 5 (Tarboton, 2015). Para obter as variáveis morfométricas da bacia foi utilizado o programa Idrisi (Eastman, 2012) com o complemento Gestión Integrada del Agua con Idrisi (GIAI).

Para a delimitação de cada uma das bacias analisadas, foram utilizadas seis imagens do sensor ASTER GDEM (ASTER GDEM é um produto do METI e NASA) denominadas ASTGTM2_S25W054_dem, ASTGTM2_S25W055_dem, ASTGTM2_S26W054_dem, ASTGTM2 _S26W055_dem, ASTGTM2_S27W054_dem, ASTGTM2 _S27W055_dem obtidas da United States Geological Survey (USGS), concebidas em 2011.

Os resultados da hidrografia obtidos a partir da análise anterior foram comparados com os resultados da Agência Nacional de Águas (ANA) (2015), gerados por meio de cartografia digital para a bacia do Rio Iguaçu a partir das bases cartográficas recentes elaboradas pelos Estados do Paraná (1:50.000) e Santa Catarina (1:25.000) (ANA, 2015).

Para obtenção das áreas de drenagem das bacias, foram utilizadas seis imagens ASTER processadas no ambiente SIG com auxílio do software QGIS versão 2.8, com o Sistema de Referência Geocêntrico Mundial (WGS 84) UTM zona 22 S. Após esse procedimento, as imagens foram unidas, para posterior extração da área de interesse. Em seguida os dados foram orientados ao Sistema de Referência Geocêntrico para as Américas (SIRGAS) (2000).

O complemento TauDEM (Tarboton, 2015) deriva informações hidrologicamente úteis a partir de dados MDT (Modelo Digital de Terreno, possui vários algoritmos e funciona como complemento do QGIS. Em seguida, os dados foram submetidos ao processo de análise morfométrica para obtenção da hierarquia fluvial segundo método de Strahler (1952), cursos de água e área. Após a delimitação, foram calculados os índices de descrição das características geométricas, do relevo e rede de drenagem das bacias conforme especificadas no Quadro 1. Essas características foram comparadas com dados de hidrografia obtidos pela ANA (2015).

\section{Características geométricas}

Os padrões de drenagem estão relacionados à disposição espacial dos cursos fluviais, influenciados pela natureza e disposição das camadas rochosas, declividade, altimetria, evolução geológica e geomorfológica da região (Mioto et al., 2014).

Do ponto de vista geométrico, têm-se os seguintes padrões de drenagem, de acordo com Christofoletti (1980): dendrítico (regiões de estruturas sedimentares horizontais com rochas de resistência uniforme); treliça (regiões de estruturas sedimentares homoclinais, em estruturas falhadas e nas cristas com sentidos opostos); paralela (regiões com forte controle estrutural e vertentes escarpadas); radial (pode se desenvolver sobre variados embasamentos e estruturas), com forma centrífuga e centrípeta; ou ainda, anelar (estruturas com camadas duras e frágeis). 
Para determinação da forma das bacias foram utilizados os índices fator de forma $(K f)$, coeficiente de compacidade $(K c)$ e o índice de circularidade $(I c)$. O primeiro índice utilizado foi o $K f$, que relaciona a forma da bacia com a de um retângulo (Oliveira et al., 2010) - Quadro 1.

O $K f$ é a razão entre a largura média e o comprimento axial da bacia. Mede-se o comprimento da bacia $(L)$ quando se segue o curso de água mais longo desde a desembocadura até a cabeceira mais distante na bacia. A largura média $(\bar{L})$ é obtida dividindo a área pelo comprimento da bacia. Sua fórmula final, representa a divisão da área $\left(\mathrm{km}^{2}\right)$ pelo comprimento ao quadrado $(\mathrm{km})$. O fator de forma é um indicativo da tendência de enchente. Assim, a tendência de enchente será menor na bacia com fator de forma menor, quando comparada a outra de mesmo tamanho, mas com fator de forma maior (Villela \& Mattos, 1975).

Figura 1: Representação da área de estudo. Os rios analisados foram Andrada, Monteiro, Gonçalves Dias, Floriano, Silva Jardim, Cotejipe, Sarandi, Capanema e Santo Antônio.

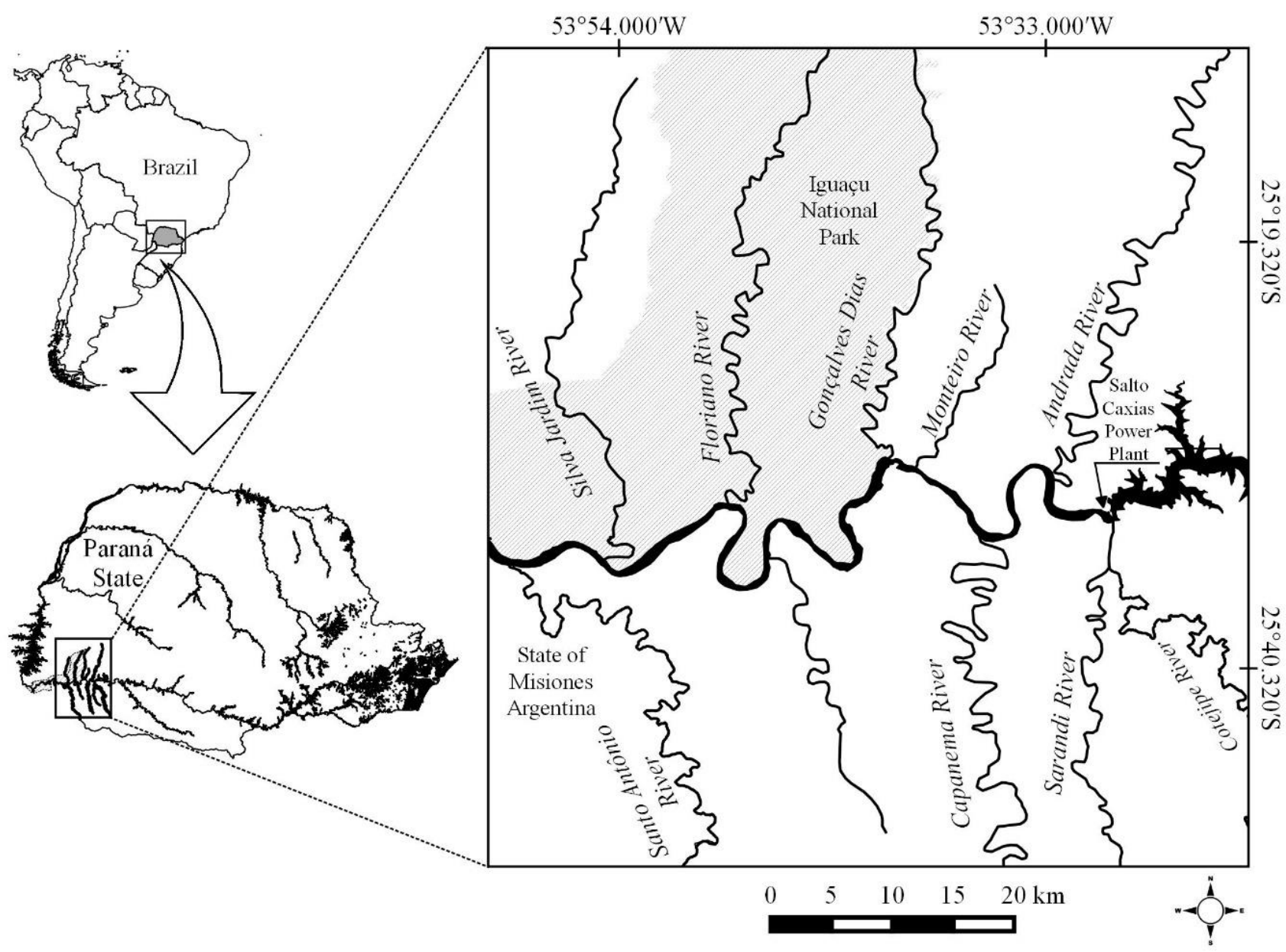

Fonte: Elaborada pelos autores. 
Posteriormente, calculou-se o coeficiente de compacidade $(K c)$, que relaciona a forma da bacia com um círculo. Constitui a relação entre perímetro da bacia e a circunferência de um círculo de área igual à da bacia (Tonello et al., 2006). Bacias com forma aproximada à de um círculo tendem a direcionar o escoamento superficial para um trecho pequeno do rio principal. Portanto, quanto mais próximo a 1 for o resultado, maior a potencialidade de picos de enchentes na bacia hidrográfica (Oliveira et al., 2010).

Posteriormente, calculou-se o índice de circularidade (Ic), que em conjunto ao $K c$, tende para a unidade à medida que a bacia se aproxima da forma circular e diminui à medida que a forma se torna alongada. É a relação entre a área total da bacia e um círculo de perímetro igual a área da bacia ao quadrado. (Cardoso et al., 2006; Tonello et al., 2006). Para o Ic, valores menores que 0,51 indicam que a bacia tende a forma alongada. Valores maiores sugerem que a bacia tende a ser circular, favorecendo os processos de inundação (Schumm, 1956).

\section{Características de relevo}

Para determinar as características de relevo, foram calculadas a altitude inicial ( $A i)$, altitude média $(A m)$, elevação média $(E m)$ e declividade média $(D m)$ com o programa Idrisi com o módulo GIAI (Quadro 1).

Os mapas de declividade foram realizados utilizando as classes definidas pela Empresa Brasileira de Pesquisa Agropecuária (Embrapa) (1979) (Tabela 1). A declividade do terreno é expressa como a variação de altitude entre dois pontos em relação à distância que os separa (Tonello et al., 2006).

Tabela 1: Classes de declividade do terreno.

\begin{tabular}{ll}
\hline Declividade & Descrição \\
\hline $0-3 \%$ & Relevo plano \\
$3-8 \%$ & Relevo suave ondulado \\
$8-20 \%$ & Relevo ondulado \\
$20-45 \%$ & Relevo fortemente ondulado \\
$45-75 \%$ & Relevo montanhoso \\
$>75 \%$ & Relevo fortemente montanhoso \\
\hline
\end{tabular}

Fonte: Embrapa (1979).

Foram realizados mapas de declividade em conjunto com o sistema fluvial e sua respectiva hierarquia. As bacias foram reunidas e distribuídas entre margem esquerda e direita do rio Iguaçu, devido a quantidade de bacias estudadas.

\section{Características de rede de drenagem}

A partir dos dados de rede de drenagem, obteve-se o número de cursos de água $(N)$, o comprimento verdadeiro do curso de água principal ( $C v r)$, o comprimento direto do curso de água principal $(C d r)$, número dos cursos por ordem $(N o)$ e comprimento total dos cursos de água $(C t)$ identificados em cada bacia (Quadro 1). Foram calculadas ainda as densidades de rios (Dr) e de drenagem (Dd), o coefiente de manutenção (Cm) e o índice de sinuosidade (Is).

A densidade de rios $(D r)$, que é a relação existente entre o número de cursos de água de primeira ordem e a área da bacia hidrográfica (Horton, 1945), tem por finalidade comparar a frequência ou a quantidade de nascentes existentes em uma área $\left(\mathrm{km}^{2}\right)$, importante por representar o comportamento hidrográfico de determinada área, estimando a capacidade de gerar novos canais (Christofoletti, 1980).

A densidade de drenagem $(D d)$ definida por Horton (1945), relaciona o comprimento total dos canais de escoamento com a área da bacia hidrográfica. Essa análise indica o nível de desenvolvimento do sistema de drenagem da bacia 
hidrográfica, revelando sua eficiência (Oliveira et al., 2010). Segundo Lana et al., (2001), se relaciona com processos climáticos na área estudada, para um mesmo tipo de clima, a $D d$ depende do comportamento hidrológico das rochas. Em relevos mais impermeáveis, as condições para o escoamento superficial são melhores, possibilitando a formação de canais e aumentando a densidade de drenagem (Lana et al., 2001).

O coeficiente de manutenção $(\mathrm{Cm})$ proposto por Schumm (1956), é tido como a expressão quantitativa de um dos valores numéricos mais importantes característicos de um sistema de drenagem: a área mínima de limitação necessária para o desenvolvimento de cada metro de canal de drenagem (Christofoletti, 1979; Santos et al., 2012). Junto com a $D d$, esta constante pode comparar a erodibilidade ou outros fatores que afetam a erosão superficial e desenvolvimento da rede de drenagem. O comprimento do fluxo terrestre é igual ao recíproco de duas vezes a densidade de drenagem (Schumm, 1956).

Por fim calculou-se o índice de sinuosidade (Is), proposto por Schumm (1963). Este índice relaciona o comprimento verdadeiro do canal principal com a distância vetorial entre os extremos do canal. Valores próximos a 1,0 indicam a tendência do canal a ser retilíneo. Valores superiores a 2,0 sugerem canais tortuosos e valores intermediários indicam formas transicionais, regulares e irregulares (Lana et al., 2001). As correntes sinuosas são caracterizadas por baixa relação larguraprofundidade, alta porcentagem de silte-argila no perímetro do canal, nos bancos, e gradiente mais baixo do que canais retos com a mesma descarga média.

Quadro 1: Variáveis morfométricas e suas respectivas unidades de medidas.

\begin{tabular}{|c|c|c|}
\hline Características geométricas & Siglas / Fórmula & Significado \\
\hline Área total $\left(\mathrm{km}^{2}\right)$ & $A t$ & - \\
\hline Perímetro total $\left(\mathrm{km}^{2}\right)$ & $P t$ & $(-\ldots \ldots \ldots \ldots$ \\
\hline $\begin{array}{l}\text { Coeficiente de compacidade (Gravelius, 1914; } \\
\text { Bendjoudi \& Hubert, 2002) }\end{array}$ & $K c=0,28 P / \sqrt{ } A$ & $\begin{array}{l}\text { Kc=coeficiente de compacidade, } \\
\mathrm{P}=\text { perímetro e } \mathrm{A}=\text { área da bacia }\end{array}$ \\
\hline Fator de forma (Gravelius, 1914) & $K f=A / L^{2}$ & $\begin{array}{l}\mathrm{Kf}=\text { fator de forma, } \mathrm{A}=\text { área da bacia e } \\
\mathrm{L}=\text { comprimento da bacia }\end{array}$ \\
\hline Índice de circularidade (Miller, 1953) & $I c=\left(12,57^{*} A\right) / P^{2}$ & 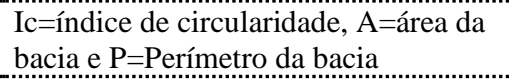 \\
\hline Padrão de drenagem (Christofoletti, 1980) & $P d$ & - \\
\hline Características do relevo & & - \\
\hline $\begin{array}{l}\text { Altitude inicial em Msnm (metros sobre o } \\
\text { nível do mar) }\end{array}$ & $A i$ & - \\
\hline Altitude média em Msnm & $A m$ & - \\
\hline Elevação média em Msnm & $E m$ & - \\
\hline Declividade média em graus & Dmg & - \\
\hline Declividade média em porcentagem & Dmp & - \\
\hline Características da rede de drenagem & & - \\
\hline Número de rios total & $N$ & - \\
\hline Número de rios por ordem (Strahler, 1952) & No & - \\
\hline Comprimento verdadeiro do rio principal $(\mathrm{km})$ & $C r p$ & - \\
\hline $\begin{array}{l}\text { Comprimento direto do rio principal }(\mathrm{km}) \text { - } \\
\text { linha reta traçada da foz até a nascente mais } \\
\text { distante }\end{array}$ & Crpd & - \\
\hline Comprimento total dos rios $(\mathrm{km})$ & $C t$ & 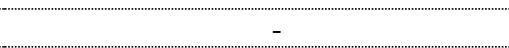 \\
\hline $\begin{array}{l}\text { Densidade de rios (Horton, 1945), com a } \\
\text { hierarquia (Strahler, 1952), } 1^{\text {a }} \text { ordem }\end{array}$ & $D r=N / A$ & $\begin{array}{l}\mathrm{Dr}=\text { densidade de rios, } \mathrm{N}=\text { número total } \\
\text { de rios na bacia e } \mathrm{A}=\text { área da bacia }\end{array}$ \\
\hline $\begin{array}{l}\text { Densidade de drenagem } \\
\text { (Horton, 1945) }\end{array}$ & $D d=L t / A$ & $\begin{array}{l}\mathrm{Dd}=\text { densidade de drenagem, } \\
\mathrm{Lt}=\text { comprimento total dos canais e } \\
\mathrm{A}=\text { área da bacia }\end{array}$ \\
\hline $\begin{array}{l}\text { Coeficiente de manutenção } \\
\text { (Schumm, 1956) }\end{array}$ & $C m=1 / D d^{*} 1001$ & $\begin{array}{l}\mathrm{Cm}=\text { coeficiente de manutenção, } \\
\mathrm{Dr}=\text { densidade de drenagem }\end{array}$ \\
\hline Índice de sinuosidade (Schumm, 1963) & $I s=L / D v$ & $\begin{array}{l}\text { Is=índice de sinuosidade, } \\
\mathrm{L}=\text { comprimento do canal principal e } \\
\text { Dv=distância }\end{array}$ \\
\hline
\end{tabular}




\section{Resultados e Discussão}

A declividade da região é predominantemente ondulada, variando entre suave ondulado e fortemente ondulado, poucas áreas escarpadas (Tabela 2), com drenagem dendrítica (Tabela, 3) nas quais os canais apresentam formato arborescente. A bacia Capanema possui maior área $\left(1.967 \mathrm{~km}^{2}\right)$ e perímetro $(384,12 \mathrm{~km})$, seguida pelo Andrada, com área $\left(1.400 \mathrm{~km}^{2}\right) \mathrm{e}$ perímetro $(297,42 \mathrm{~km})$. A bacia que possui menor área e perímetro é a bacia Monteiro, com 113,39 km² e 75,18 km. No entanto, sabe-se que bacias hidrográficas resultam de processos dinâmicos que podem ocasionar alterações no seu perímetro e área ao longo do tempo.

As bacias tendem a concentrar a água da chuva por um tempo maior de acordo com o coeficiente de compacidade $(K c)$ apresentou valores afastados da unidade e o fator de forma $(\mathrm{Kf})$ exibiu valores baixos para todas as bacias. Esses valores indicam que as bacias não possuem formatos semelhantes ao de um círculo, sendo bacias alongadas. Os resultados obtidos podem ser comprovados pelo índice de circularidade (Ic) com valores muito distantes da unidade (Tabela 3). Esse resultado corrobora inferências propostas por Tonello et al. (2006) e Mioto et al. (2014), com resultados semelhantes, relacionados ao tempo de concentração maior, formas alongadas e pouca tendência a enchentes.

Em relação ao relevo, os resultados correspondentes a altitude, elevação e declividade - $A i, A m, E m$ e $D m$ (Tabela 3) a bacia do rio Cotejipe apresentou os maiores valores para $A i(766 \mathrm{~m})$ e $A m(268 \mathrm{~m})$. A bacia do rio Monteiro possui a menor $A i(478 \mathrm{~m})$ e a bacia do rio Santo Antônio possui o menor valor para Am (208 m). A bacia do rio Capanema apresentou a maior Dmp (19,91\%), seguida pela bacia do rio Cotejipe $(16,77 \%)$ e a bacia do rio Sarandi apresenta menor Dmp $(11,97 \%)$ (Tabela 3). Este resultado corrobora com o mapa de declividade (Figuras 2A e 2B). As paisagens das bacias dos rios Monteiros e Sarandi segundo Celestino et al. (2019) encontra-se fragmentadas.

Quase todas as bacias apresentaram relevo ondulado (8 a 20\%), com exceção da bacia do rio Capanema, que apresentou o relevo forte ondulado, possuindo maior declividade em sua cabeceira. A bacia do rio Capanema apresenta maior área com relevo forte ondulado (40,58\%), relevo montanhoso (4,02\%) e escarpado (0,06\%) (Tabela 2). Essa informação também é representada no mapa de declividade (Figura 2A e 2B).

Tabela 2: Porcentagem de áreas de declividade distribuídas pelas classes de declividade para as bacias.

\begin{tabular}{|c|c|c|c|c|c|c|c|c|c|}
\hline \multirow[b]{2}{*}{$\begin{array}{l}\text { Classes de } \\
\text { Declividade }\end{array}$} & \multicolumn{9}{|c|}{ Bacias Hidrográficas } \\
\hline & & 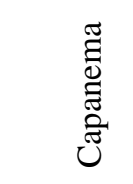 & 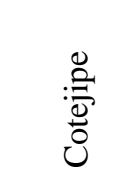 & 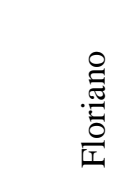 & 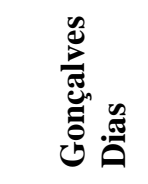 & 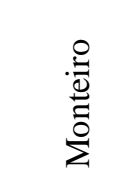 & 总器 & 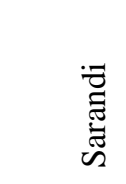 & 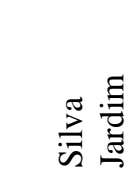 \\
\hline $\begin{array}{l}\text { 1-Plano } \\
(0-3 \%)\end{array}$ & 6,402 & 5,605 & 6,568 & 6,002 & 6,215 & 7,637 & 9,348 & 10,027 & 10,642 \\
\hline $\begin{array}{l}\text { 2-Suave ondulado } \\
(3-8 \%)\end{array}$ & 18,319 & 12,222 & 16,439 & 19,715 & 17,870 & 21,470 & 24,285 & 26,487 & 25,391 \\
\hline $\begin{array}{l}\text { 3-Ondulado } \\
(8-20 \%)\end{array}$ & 46,708 & 37,503 & 43,581 & 52,544 & 50,070 & 51,649 & 48,412 & 49,148 & 47,115 \\
\hline $\begin{array}{l}\text { 4-Fortemente ondulado } \\
(20-45 \%)\end{array}$ & 26,586 & 40,584 & 31,544 & 21,180 & 24,991 & 18,950 & 17,433 & 13,716 & 16,301 \\
\hline $\begin{array}{l}\text { 5-Montanhoso } \\
\text { (45-75\% }\end{array}$ & 1,968 & 4,021 & 1,849 & 0,559 & 0,853 & 0,291 & 0,5200 & 0,622 & 0,550 \\
\hline $\begin{array}{l}\text { 6- Escarpado } \\
(>75 \%)\end{array}$ & 0,016 & 0,065 & 0,018 & 0,002 & 0,001 & 0,002 & 0,002 & - & - \\
\hline
\end{tabular}

Fonte: Elaborada pelos autores. 
As bacias dos rios Sarandi e Silva Jardim não apresentaram relevo escarpado, evidenciando que suas áreas possuem declividade menor em relação as demais bacias. A bacia do Sarandi possui $10,02 \%$ de sua área plana e a bacia Silva Jardim $10,64 \%$.

O conhecimento do relevo da superfície terrestre em bacias hidrográficas, associados à sua declividade, como locais suscetíveis à desabamentos, erosões e assoreamentos auxiliam no monitoramento de áreas com possíveis riscos ambientais. Por outro lado, ajudam também na identificação de áreas favoráveis ao desenvolvimento da fauna aquática, como peixes migradores, que buscam ambientes com a formação de remansos e/ou lagoas para serem utilizados como berçários para o desenvolvimento das larvas (Simas et al., 2014). Assim, as bacias dos rios Capanema, Andrada e Cotejipe chamam atenção quanto aos riscos ambientais e dos rios Sarandi, Silva Jardim, Santo Antônio e Monteiro, como possibilidades para prospecção de áreas de reprodução e desenvolvimento inicial de peixes.

As características da rede de drenagem mostraram que as bacias do Capanema, Andrada e Santo Antônio se destacaram quanto ao número de rios $(\mathrm{N})$, número de rios por ordem (No), e comprimentos (Cvr, Cdr e CT), sendo as bacias com as maiores dimensões, a primeira e a última afluentes da margem direita do rio Iguaçu (Tabela 3).

Na comparação visual dos dados com aqueles advindos da base cartográfica da ANA (2015) (Figura 4) notou-se que os resultados obtidos têm uma precisão menor, provavelmente pela diferença na escala utilizada. Nesse estudo os dados advém de um Modelo Digital de Terreno (MDT) de 30 m, disponibilizado em 2011 e os dados da ANA (2015), são provenientes da cartografia, sendo mais precisos e utilizados para escalas menores. As informações obtidas por meio do MDT são apropriadas para grandes escalas e utilizadas nesse estudo para quantificar preferencialmente os cursos de água, buscando maior acurácia com a realidade, para rios que permanecem fluindo durante todo o ano. 
Figura 2: A: Representação cartográfica da declividade nas bacias estudadas na margem direita do rio Iguaçu e sua hierarquia fluvial. Cada letra representa uma bacia, sendo: $\mathrm{A}=$ Silva Jardim, $\mathrm{B}=$ Floriano, $\mathrm{C}=$ Gonçalves Dias, $\mathrm{D}=\mathrm{Monteiro}$ e $\mathrm{E}=$ Andrada. (As cores devem ser consideradas na impressão).

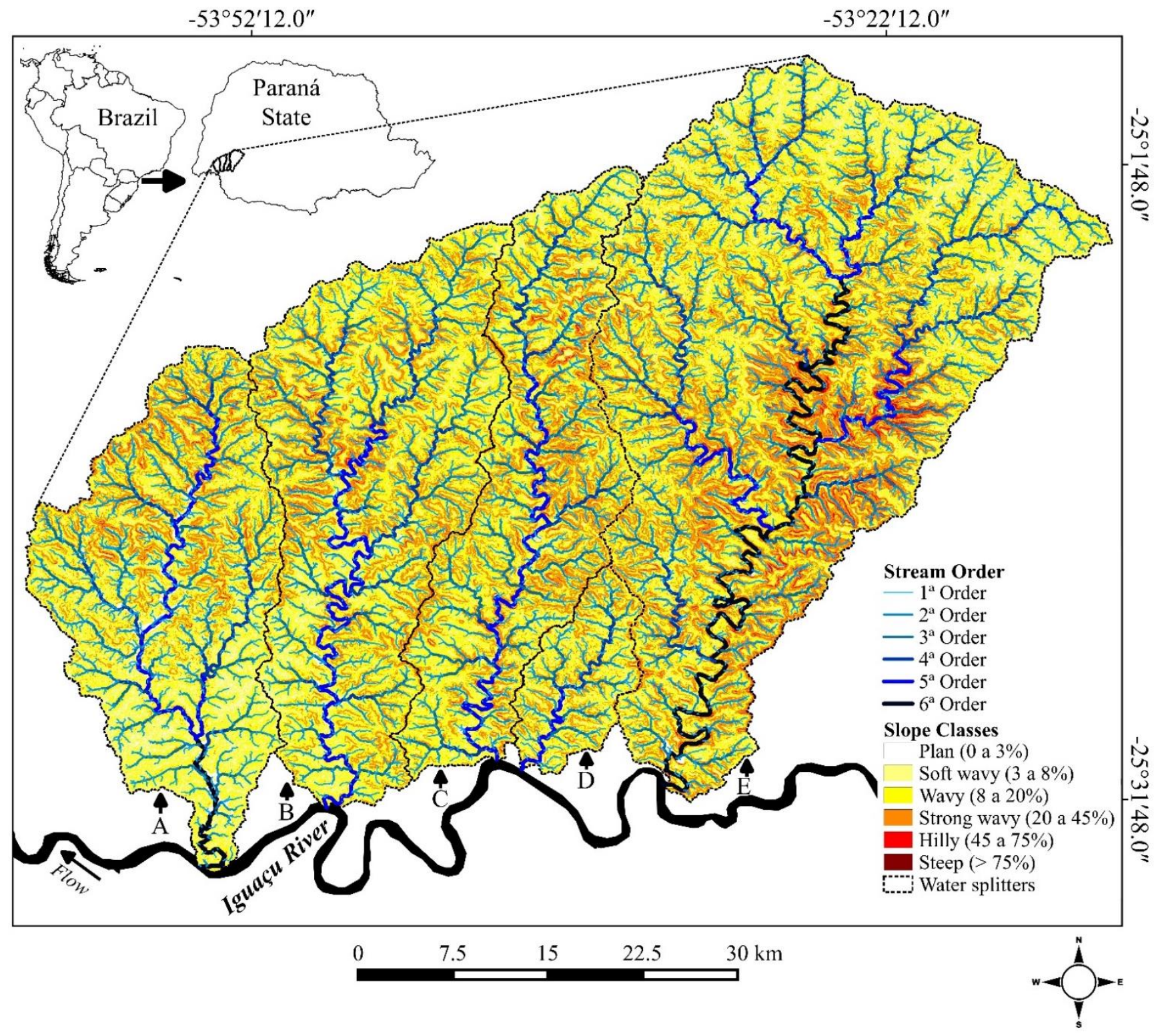

Fonte: Elaborada pelos autores. 
Figura 2: B: Representação cartográfica da declividade nas bacias estudadas na margem direita do rio Iguaçu e sua hierarquia fluvial. Cada letra representa uma bacia, sendo: $\mathrm{A}=$ Santo Antônio, $\mathrm{B}=$ Capanema, $\mathrm{C}=\mathrm{Sarandi}$, D = Cotejipe. (As cores devem ser consideradas na impressão).

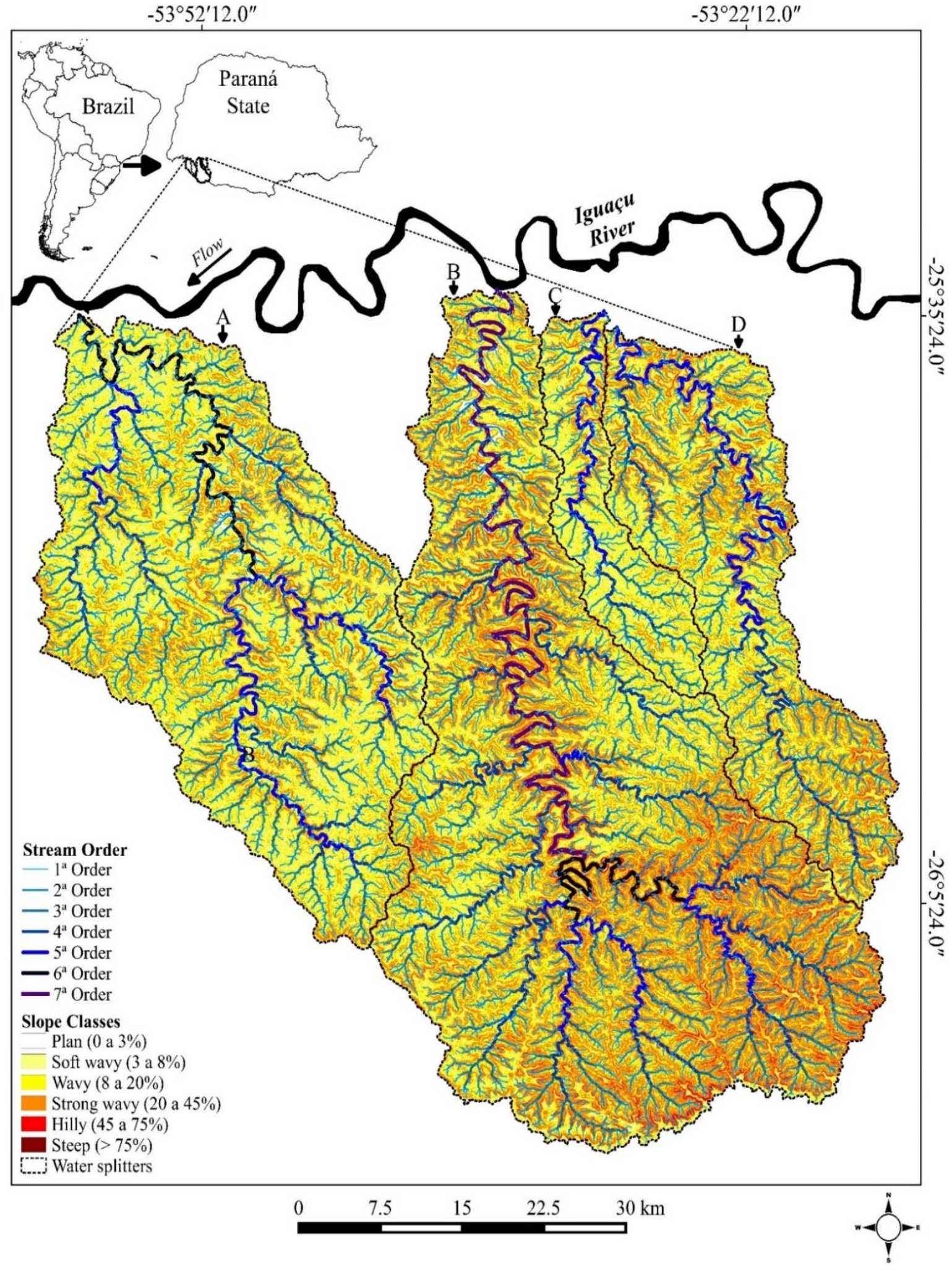

Fonte: Elaborada pelos autores. 
A densidade de rios com hierarquia primeira ordem, que está relacionada à densidade de nascentes de cursos de água perenes, foi maior para o a bacia do rio Santo Antônio ( $\operatorname{~rr} 1,46$ cursos de água por $\mathrm{km}^{2}$ ) e menor para a bacia do rio Capanema ( $\operatorname{Dr} 1,25$ cursos de água por $\mathrm{km}^{2}$ ) - Tabela 3. Os dados obtidos pela ANA (2015) elaborados a partir de cartas topográficas, apresentam maior quantidade de nascentes em relação as bacias dos rios Santo Antônio e Capanema, respectivamente. Aparentemente esses dados foram quantificados buscando cursos de água perenes e efêmeros, devido à alta quantidade de nascentes presentes. Os resultados deste estudo referem-se a busca de cursos de água perenes, o que explica a diferença entre os dois tipos de dados.

O rio Santo Antônio combina uma alta densidade de rios, baixa declividade com terreno ondulado e suave ondulado, enquanto o Capanema tem a menor densidade de rios e a maior declividade média, com predominância de áreas ondulada e fortemente ondulada (Tabela 3), que indicam a ocorrência de encostas mais íngremes. O resultado coincide com o proposto por Horton (1945), em que a $\mathrm{Dr}$ pode variar muito dependendo da área da bacia. Este efeito pode ser mascarado pelo aumento da densidade de drenagem e frequência de corrente nas encostas mais íngremes, geralmente adjacentes a bacias de drenagem menores.

A densidade de drenagem $(D d)$ mostrou que a bacia do rio Sarandi apresenta maior valor $\left(1,54 \mathrm{~km} / \mathrm{km}^{2}\right)$ e a bacia do rio Floriano apresentou menor valor $\left(1,43 \mathrm{~km} / \mathrm{km}^{2}\right)$, assim as nove bacias possuem densidade de drenagem intermediária (Tabela 3). Em relação a esta variável Villela et al. (1975), encontraram valores entre $0,5 \mathrm{~km} / \mathrm{km}^{2}$, em bacias com menor capacidade, e 3,5 km/ $\mathrm{km}^{2}$, em bacias com maior capacidade. Cardoso et al. (2006), obtiveram valores em torno de 2,35 $\mathrm{km} / \mathrm{km}^{2} \mathrm{e}$, também, indicaram uma drenagem intermediária. Mioto et al. (2014), encontraram valores ainda menores $(0,72$ $\mathrm{km} / \mathrm{km}^{2}$ ) do que aqueles registrados neste estudo. Desse modo, as noves bacias têm densidade de drenagem intermediária a baixa. Regiões com baixa densidade de drenagem estão geralmente associadas a áreas com rochas permeáveis e de regime pluviométrico caracterizado por chuvas de baixa intensidade ou pouca concentração de precipitação (Tonello et al., 2006). O comportamento hidrológico das rochas possui influência sobre a $D d$. 
Figura 3: Hidrografia da bacia do Rio Monteiro, com os dados obtidos pela delimitação (A) e os dados obtidos da ANA (2015) (B). O mapa C representa os dados sobrepostos. (As cores devem ser consideradas na impressão).
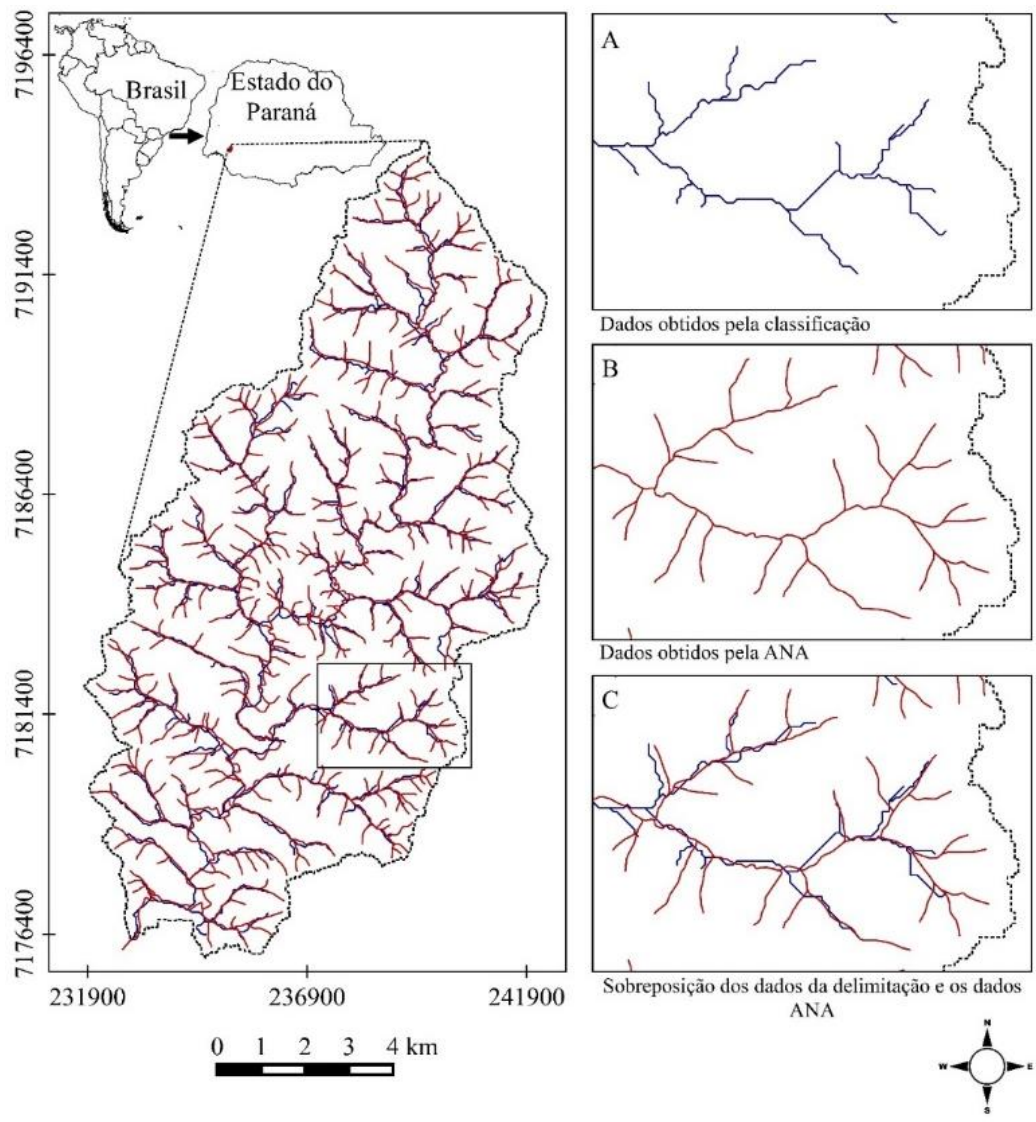

Fonte: Elaborada pelos autores.

Segundo Christofoletti (1980), as rochas onde a infiltração encontra maior dificuldade há condições melhores para o escoamento superficial. Essa característica garante possibilidades para a esculturação de canais, como entre rochas de granulação fina, gerando uma densidade de drenagem mais elevada. O contrário ocorre com as rochas de granulometria grossa, que possuem capacidades de infiltração maiores.

O $\mathrm{Cm}$ da bacia do rio Floriano obteve o maior valor $(698,17 \mathrm{~m} 2 / \mathrm{m})$, seguido pela bacia do rio Andrada $(692,52$ $\left.\mathrm{m}^{2} / \mathrm{m}\right)$. A bacia do rio Sarandi apresentou menor Cm $\left(650,77 \mathrm{~m}^{2} / \mathrm{m}\right)$ seguida pela bacia do rio Santo Antônio $\left(658,34 \mathrm{~m}^{2} / \mathrm{m}\right)$. Esses valores representam a área mínima necessária para a manutenção de um metro de canal de escoamento. Comparando o maior valor obtido com o resultado de Stipp, Campos e Caviglione (2010), que obtiveram $C m$ alto, coincidindo com a $D r$, que apresentou valor alto, atribuindo este resultado as baixas declividades e boa capacidade de recarga hídrica.

Isso pode ocorrer na área de estudo, pois algumas bacias apresentam declividades intermediarias em grande parte de sua área, como a bacia dos rios Floriano e Andrada (Tabela 3). A bacia do rio Floriano obteve maior área com relevo ondulado, e uma $\mathrm{Dr}$ alta (1,30 cursos de água por $\left.\mathrm{km}^{2}\right)$ possuindo influência no $\mathrm{Cm}$, apresentou maior área para manutenção de um metro de canal de escoamento. No caso da bacia do rio Andrada, com relevo ondulado de $46,70 \%$, possuindo um percentual alto de declividade baixa, mas também influenciou muito o $\mathrm{Cm}$, necessitando também de uma área grande para manutenção do canal de drenagem. Os rios Sarandi e Santo Antônio, por outro lado necessitam de uma área menor para manutenção dos seus canais, ambos com área de declividade menor e predomínio de relevo suave ondulado e ondulado. 
O Is obtido mostrou que a bacia do rio Capanema apresentou maior valor $(2,48)$ sugerindo que o canal principal é tortuoso. Além deste resultado, valores superiores a 2,0

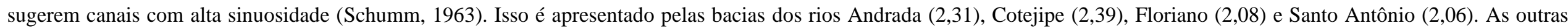

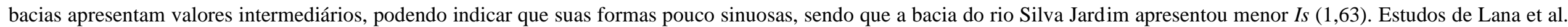

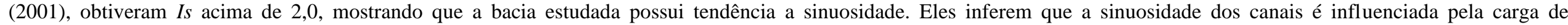
sedimentos, que podem se acumular, compartimentação litológica, estruturação geológica e declividade dos canais, ocorrendo nas bacias que apresentam alta sinuosidade.

Tabela 3: Variáveis morfométricas analisadas para as nove bacias hidrográficas.

\begin{tabular}{|c|c|c|c|c|c|c|c|c|c|c|}
\hline Características geométricas & Siglas & Andrada & Capanema & Cotejipe & Floriano & $\begin{array}{r}\text { Gonçalves } \\
\text { Dias } \\
\end{array}$ & Monteiro & $\begin{array}{r}\text { Santo } \\
\text { Antônio } \\
\end{array}$ & Sarandi & Silva Jardim \\
\hline Área total $\left(\mathrm{km}^{2}\right)$ & At & 1400,52 & 1967,43 & 634,68 & 676,56 & 494,34 & 113,39 & 1279,27 & 228,35 & 572,64 \\
\hline Perímetro total $(\mathrm{km})$ & $\mathrm{Pt}$ & 297,42 & 384,12 & 229,20 & 212,10 & 218,28 & 75,18 & 271,80 & 146,76 & 187,86 \\
\hline $\begin{array}{l}\text { Coeficiente de compacidade (Gravelius, 1914; Bendjoudi, } \\
\text { et al., 2002) }\end{array}$ & $\mathrm{Kc}$ & 2,24 & 2,44 & 2,57 & 2,30 & 2,77 & 1,99 & 2,14 & 2,74 & 2,21 \\
\hline Fator de forma (Gravelius, 1914) & $\mathrm{Kf}$ & 0,07 & 0,05 & 0,03 & 0,06 & 0,06 & 0,12 & 0,07 & 0,05 & 0,11 \\
\hline Índice de circularidade (Miller, 1953) & Ic & 0,20 & 0,17 & 0,15 & 0,19 & 0,13 & 0,25 & 0,22 & 0,13 & 0,20 \\
\hline Padrão de drenagem (Christofoletti, 1980) & $\mathrm{Pd}$ & Dendrítico & Dendrítico & Dendrítico & Dendrítico & Dendrítico & Dendrítico & Dendrítico & Dendrítico & Dendrítico \\
\hline \multicolumn{11}{|l|}{ Características do relevo } \\
\hline Altitude inicial em Msnm (metros sobre o nível do mar) & $\mathrm{Ai}$ & 714,00 & 671,00 & 766,00 & 678,00 & 741,00 & 478,00 & 558,00 & 608,00 & 548,00 \\
\hline Altitude média em Msnm & $\mathrm{Am}$ & 262,00 & 260,00 & 268,00 & 224,00 & 251,00 & 252,00 & 208,00 & 268,00 & 221,00 \\
\hline Elevação média em Msnm & Em & 576,62 & 535,07 & 533,39 & 450,45 & 490,64 & 370,67 & 399,97 & 457,11 & 365,57 \\
\hline Declividade média em graus & Dmg & 8,90 & 11,06 & 9,38 & 7,90 & 8,42 & 7,55 & 7,19 & 6,76 & 6,94 \\
\hline Declividade média em porcentagem & Dmp & 15,90 & 19,91 & 16,77 & 14,02 & 14,98 & 13,37 & 12,76 & 11,97 & 12,30 \\
\hline \multicolumn{11}{|l|}{ Características da rede de drenagem } \\
\hline Número de rios & $\mathrm{N}$ & $2.446,00$ & $3.104,00$ & $1.061,00$ & $1.092,00$ & 875,00 & 202,00 & $2.325,00$ & 392,00 & $1.062,00$ \\
\hline Número de rios por ordem (Strahler, 1952) & No & $\begin{array}{r}1^{\mathrm{a}} 1.942 / \\
2^{\mathrm{a}} 392 / 3^{\mathrm{a}} \\
91 / 4^{\mathrm{a}} 16 / \\
5^{\mathrm{a}} 4 / 6^{\mathrm{a}} 1\end{array}$ & $\begin{array}{r}1^{\mathrm{a}} 2.466 / \\
2^{\mathrm{a}} 501 / 3^{\mathrm{a}} \\
107 / 4^{\mathrm{a}} 21 \\
/ 5^{\mathrm{a}} 6 / 6^{\mathrm{a}} 2 \\
/ 7^{\mathrm{a}} 1 \\
\end{array}$ & $\begin{array}{l}1^{\mathrm{a}} 848 / 2^{\mathrm{a}} \\
176 / 3^{\mathrm{a}} 32 \\
/ 4^{\mathrm{a}} 4 / 5^{\mathrm{a}} 1\end{array}$ & $\begin{array}{l}1^{\mathrm{a}} 878 / 2^{\mathrm{a}} \\
166 / 3^{\mathrm{a}} 38 \\
/ 4^{\mathrm{a}} 9 / 5^{\mathrm{a}} 1\end{array}$ & $\begin{array}{r}1^{\mathrm{a}} 689 / 2^{\mathrm{a}} \\
142 / 3^{\mathrm{a}} 34 / \\
4^{\mathrm{a}} 9 / 5^{\mathrm{a}} 1\end{array}$ & $\begin{array}{r}1^{\mathrm{a}} 156 / 2^{\mathrm{a}} \\
33 / 3^{\mathrm{a}} 10 / \\
4^{\mathrm{a}} 2 / 5^{\mathrm{a}} 1\end{array}$ & $\begin{array}{r}1^{\mathrm{a}} 1.866 / 2^{\mathrm{a}} \\
358 / 3^{\mathrm{a}} 83 / \\
4^{\mathrm{a}} 14 / 5^{\mathrm{a}} 3 / \\
6^{\mathrm{a}} 1\end{array}$ & $\begin{array}{r}1^{\mathrm{a}} 314 / 2^{\mathrm{a}} \\
65 / 3^{\mathrm{a}} 10 / \\
4^{\mathrm{a}} 2 / 5^{\mathrm{a}} 1\end{array}$ & $\begin{array}{r}1^{\mathrm{a}} 830 / 2^{\mathrm{a}} \\
177 / 3^{\mathrm{a}} 44 \\
/ 4^{\mathrm{a}} 8 / 5^{\mathrm{a}} 2 / \\
6^{\mathrm{a}} 1\end{array}$ \\
\hline Comprimento verdadeiro do rio principal (km) & $\mathrm{Cvr}$ & 145,10 & 199,17 & 138,09 & 108,43 & 93,80 & 30,61 & 130,87 & 67,34 & 72,28 \\
\hline
\end{tabular}


Research, Society and Development, v. 11, n. 2, e42811225698, 2022

(CC BY 4.0) | ISSN 2525-3409 | DOI: http://dx.doi.org/10.33448/rsd-v11i2.25698

\begin{tabular}{|c|c|c|c|c|c|c|c|c|c|c|}
\hline $\begin{array}{l}\text { Comprimento direto do rio principal (linha reta traçada da } \\
\text { foz até a nascente mais distante) }(\mathrm{km})\end{array}$ & $\mathrm{Cdr}$ & 62,86 & 80,19 & 57,87 & 52,02 & 52,29 & 18,54 & 63,38 & 35,86 & 44,36 \\
\hline Comprimento total dos rios $(\mathrm{km})$ & $\mathrm{Ct}$ & 2022,34 & 2844,24 & 959,07 & 969,05 & 717,91 & 172,02 & 1943,17 & 350,89 & 857,89 \\
\hline $\begin{array}{l}\text { Densidade de rios (Horton, 1945), com a hierarquia } \\
\text { (Strahler, 1952), } 1^{\mathrm{a}} \text { ordem }\end{array}$ & Dr & 1,39 & 1,25 & 1,34 & 1,30 & 1,39 & 1,38 & 1,46 & 1,38 & 1,45 \\
\hline Densidade de drenagem (Horton, 1945) & $\mathrm{Dd}$ & 1,44 & 1,45 & 1,51 & 1,43 & 1,45 & 1,52 & 1,52 & 1,54 & 1,50 \\
\hline $\begin{array}{l}\text { Coeficiente de manutenção }\left(\mathrm{m}^{2}\right) \\
\text { (Schumm, 1956) }\end{array}$ & $\mathrm{Cm}$ & 692,52 & 691,73 & 661,77 & 698,17 & 688,58 & 659,17 & 658,34 & 650,77 & 667,49 \\
\hline Índice de sinuosidade (Schumm, 1963) & Is & 2,31 & 2,48 & 2,39 & 2,08 & 1,79 & 1,65 & 2,06 & 1,88 & 1,63 \\
\hline
\end{tabular}

Fonte: Elaborada pelos autores. 


\section{Conclusão}

As bacias estudadas em geral possuem formas alongadas, facilitando o escoamento, influenciado pela alta declividade nas cabeceiras de algumas das bacias, em geral média capacidade de drenagem e sinuosidade média a alta. Embora os dados utilizados tenham resolução espacial de $30 \mathrm{~m}$, apresentaram tendências semelhantes quando comparados com os dados da base da ANA (2015), produzidos através de cartas topográficas de menor escala, indicando a viabilidade do uso da metodologia MDT para estudos em escalas maiores.

Com base nos resultados obtidos, conclui se que estudos empregando técnicas de análise geomorfológica em bacias hidrográficas utilizando o MDT possibilitam avaliar de maneira sistemática regiões hidrográficas em grande escala, utilizando ferramentas de geotecnologias relativamente acessíveis sem a necessário de utilização de máquinas sofisticadas para seu processamento. As variáveis geomorfológicas das bacias hidrográficas podem apoiar a tomada de decisão tanto em relação aos riscos das atividades antrópicas quanto para a definição de áreas de conservação, especialmente de áreas de interesse para a conservação da água e dos ecossistemas aquáticos, incluindo os estoques pesqueiros. Contudo, outros estudos são encorajados nessas regiões utilizando tecnologias mais precisas e eficazes.

Os estudos de batimetria, para medição das profundidades, e geração de MDTs batimétricos, que representam o relevo abaixo da superfície da água, é uma alternativa para determinação de regiões profundas utilizadas como áreas de descanso e berçários pelos peixes. O monitoramento da ocorrência de processos erosivos e de deposição, das dimensões das áreas ocupadas pela vegetação, dos efeitos da ocupação antrópica e variações climáticas e das interfaces com outras áreas de conhecimento, são possibilidades de estudo associadas às bacias hidrográficas.

\section{Referências}

Agência Nacional de Águas - ANA. (2015). Base Hidrográfica Ottocodificada da Bacia do Rio Iguaçu. ANA. https://metadados.snirh.gov.br/geonetwork/srv/api/records/c104850f-9cda-4c09-ad6e-62248c26ded0

Ahn, S. R., \& Kim, S. J. (2019). Assessment of watershed health, vulnerability, and resilience for determining protection and restoration Priorities. Environmental Modelling \& Software, 122. https://doi.org/10.1016/j.envsoft.2017.03.014

Bendjoudi, H., \& Hubert, P. (2002). Le coefficient de compacité de Gravelius: analyse critique d'un indice de forme des bassins versants. Hydrological Sciences Journal, 47(6), 921-930. https://doi.org/10.1080/02626660209493000

Cardoso, C. A, Dias, H. C. T, Soares, C. P. B., \& Martins, S. V. (2006). Caracterização Morfométrica da Bacia Hidrográfica do Rio Debossan, Nova Friburgo, RJ. Revista Árvore, 30(2), 241-248.

Carvalho, A. P. P., Lorandi R., Collares, E. G., Lollo, J. A. D., \& Moschini, L. E. (2021). Potential water demand from the agricultural sector in hydrographic sub-basins in the southeast of the state of São Paulo-Brazil. Agriculture, Ecosystems and Environment. 319. https://doi.org/10.1016/j.agee.2021.107508

Celestino, E. F., Celestino L. F., Silva J. F. M., Kashiwaqui, E. A. L., Makrakis, M. C., \& Makrakis, S. (2019). Environmental Assessment in Neotropical Watersheds: A Multi-Factorial Approach. Sustainability, 11(2), 490. https://doi.org/10.3390/su11020490

Christofoletti, A. (1980). Geomorfologia. Edgard Blucher.

Dar, I. A., Sankar, K., \& Dar, M. A. (2010). Remote sensing technology and geographic information system modeling: an integrated approach towards the mapping of groundwater potential zones in Hardrock terrain, Mamundiyar basin. Journal of Hydrology, 394(3-4), 285-295. https://doi.org/10.1016/j.jhydrol.2010.08.022

Eastman, J. R. (2012). IDRISI Selva. Manual Version 17.0, Clark Labs, Clark University, Worcester, 45. https://clarklabs.org/wpcontent/uploads/2016/10/IDRISI-Selva-Spanish-Manual.pdf

Empresa Brasileira de Pesquisa Agropecuária (1979). Serviço Nacional de Levantamento e Conservação de Solos (SNLCS). Reunião Técnica de Levantamento de Solos, Rio de Janeiro, RJ, Brasil, 10. Recuperado de https://library.wur.nl/WebQuery/edepot/480004

Fioreze, A. P., Oliveira, L. F. C., \& Franco, A. P. B. (2010). Caracterização morfológica da bacia hidrográfica do Ribeirão Santa Bárbara, Goiás. Pesquisa Agropecuária Tropical, 40(2), 167-173. Recuperado de https://www.revistas.ufg.br/pat/article/view/3931

Freitas, H. R. A., Freitas, C. C., Rosim, S., \& Oliveira, J. R. F. (2016). Drainage networks and watersheds delineation derived from TIN based digital elevation models. Computers \& Geosciences. 92 (21-37). https://doi.org/10.1016/j.cageo.2016.04.003

Gravelius, H. (1914). Grundrifi der gesamten Gewcisserkunde, Band 1: h'lufikunde (Compendium of Hydrology, vol. 1: Rivers, in German). Goschen, Berlin, Germany. 
Grison, F., \& Kobiyama, M. (2011). Geometria hidráulica em bacias hidrográficas paranaenses. Revista Brasileira de Recursos Hídricos, 16(2), 111-131. Recuperado de https://vdocuments.com.br/reader/full/geometria-hidraulica-em-bacias-hidrograficas-servico-geologico-do-brasil

Guerra, A. J. T., \& Cunha, S. B. (1999). Geomorfologia e meio ambiente. Bertrand Brasil, Rio de Janeiro.

Horton, R. E. (1945). Erosional development of streams and their drainage basins; hydrophysical approach to quantitative morphology. Geological Society of America Bulletin, 56(3), 275-370. https://doi.org/10.1130/0016-7606(1945)56[275:EDOSAT]2.0.CO;2

Köppen, W. G., \& Geiger, R. M. (1936). Handbuch der Klimatologie. Gebrüder Borntraeger, Berlin, Germany. http://koeppen-geiger.vuwien.ac.at/pdf/Koppen_1936.pdf

Lana, C. E., Alves, J. M. P., \& Castro, P. T. A. (2001). Análise morfométrica da bacia do Rio do Tanque, MG - Brasil. Rem Revista Escola de Minas, 54(2). https://www.scielo.br/j/rem/a/ZdVsdMXsxTZ4ZzjNkG6Jmqh/?lang=pt

Lei $\mathrm{n}^{\circ}$ 9.433, de 8 de janeiro de 1997. Institui a Política Nacional de Recursos Hídricos, cria o Sistema Nacional de Gerenciamento de Recursos Hídricos, regulamenta o inciso XIX do art. ... $1^{\circ}$ da Lei n. 8.001, de 13 de março de 1990, que modificou a Lei n. 7.990 , de 28 de dezembro de 1989. http://www.planalto.gov.br/ccivil_03/leis/19433.htm

Lima, W. P. (2008). Hidrologia florestal aplicada ao manejo de bacias hidrográficas. Piracicaba-SP: Escola Superior de Agricultura Luiz de Queiroz. http://files.engflorestal.webnode.com.br/200000001-e7c75e8c14/Apostila--hidrologia-NOVA-2008.pdf

Lorandi R., \& Cançado C. J. (2002). Parâmetros físicos para gerenciamento de bacias hidrográficas. In: Schiavetti, A., \& Camargo, A. F. M. (Eds) Conceitos de bacias hidrográficas: teorias e aplicações (Cap. 2, pp. 37-65). Ilhéus-BA: Editus. http://www.uesc.br/editora/livrosdigitais2015/conceitos_de_bacias.pdf

Miguel, A. E. S., Medeiros, R. B., Decco, H. F., \& Oliveira, W. (2014) Características morfométricas do relevo e rede de drenagem da bacia hidrográfica do rio Taquaruçu/MS. Revista Brasileira de Geografia Física, 7(4), 678-690. https://doi.org/10.26848/rbgf.v7.4.p678-690

Miller, V. C. (1953). A quantitative geomorphic study of drainage basin characteristics in the Clinch Mountain area Virginia and Tennessee. Technical Report, 3. Department of Geology, Columbia University, New York.

Mioto, C. L., Ribeiro, V. O., Souza, D. M. Q., Pereira, T. V., Anache, J. A. A. \& Filho, A. C. P. (2014). Morfometria de bacias hidrográficas através de SIGs livres e gratuitos. Anuário do Instituto de Geociências - UFRJ, 37(2), 16-22. http://dx.doi.org/10.11137/2014_2_16_22

Neto, A. S. R. (2010). Análise da conjuntura agropecuária safra 2010/11. Agrometeorologia. Secretaria da Agricultura e do Abastecimento. Departamento de Economia Rural.

Nickolas, L. B. Segura C., \& Brooksc J. R. (2017). The influence of lithology on surface water sources. Hydrological Processes, 31(10), 1913-1925. https://doi.org/10.1002/hyp.11156

Nitsche, P. R., Caramori, P. H., Ricce, W. S., \& Pinto, L. F. D. (2019). Atlas Climático do Estado do Paraná. IAPAR. https://www.idrparana.pr.gov.br/Pagina/Atlas-Climatico

Oliveira, P. T. S., Sobrinho, T. A., Steffen, J. L., \& Rodrigues, D. B. B. (2010). Caracterização morfométrica de bacias hidrográficas através de dados SRTM.

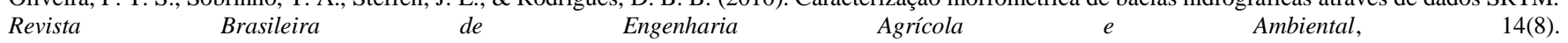
https://www.scielo.br/j/rbeaa/a/7Tzm4S4vFwVyQ6sPdKJ9qGH/abstract/?lang=pt\&format=html

Pingale, S. M., Chandra, H., Sharma, H. C., \& Mishra, S. S. (2012). Morphometric analysis of Maun watershed in Tehri-Garhwal district of Uttarakhand using GIS. International Journal $373-387$. https://www.researchgate.net/publication/254256347_Morphometric_Analysis_of_Maun_Watershed_in_Tehri-

Garhwal_District_of_Uttarakhand_Using_GIS

Pissarra, T. C. T., Politano, W., \& Ferraudo, A. S. (2004). Avaliação de características morfométricas na relação solo-superfície da bacia hidrográfica do Córrego Rico, Jaboticabal (SP). Revista Brasileira de Ciência do Solo, 28(2). https://doi.org/10.1590/S0100-06832004000200008

QGIS Development Team. (2015). QGIS Geographic Information System Developers Manual. http://www.qgis.org/

Rahaman, S. A., Ajeez, S. A., Aruchamy, S., \& Jegankumar, R. (2015). Prioritization of sub watershed based on morphometric characteristics using Fuzzy Analytical Hierarchy Process and Geographical Information System - A study of Kallar watershed, Tamil Nadu. Aquatic Procedia, 4, 1322-1330. https://doi.org/10.1016/j.aqpro.2015.02.172

Rahmati, O., Kornejady, A., Samadi, M., Nobre, A. D., \& Melesse, A. M. (2018). Development of an automated GIS tool for reproducing the HAND terrain model. Environmental Modelling \& Software, 102, 1-12. https://doi.org/10.1016/j.envsoft.2018.01.004

Reis, J. T., \& Pereira Filho,W. (2006). Influência do uso e ocupação da terra no ecossistema aquático da sub-bacia hidrográfica do Arroio Cadena, em Santa Maria, RS. Ciência E Natura, 28(1), 75-90. https://doi.org/10.5902/2179460X9715

Roni, P., Hanson, K., Beechie, T., Pess, G., Pollock, M., \& Bartley, D. M. (2005). Habitat rehabilitation for inland fisheries. Global review of effectiveness and guidance for rehabilitation of freshwater ecosystems. FAO Fisheries Technical Paper (484), FAO: Rome. https://www.fao.org/3/a0039e/a0039e.pdf

Santos, A. M.; Targa, M. S.; Batista, G. T., \& Dias, N. W. (2012). Análise morfométrica das sub-bacias hidrográficas Perdizes e Fojo no município de Campos do Jordão, SP, Brasil. Ambi-Agua, 7(3), 195-211. http://dx.doi.org/10.4136/ambi-agua.945

Schumm, S. A. (1956). Evolution of drainage systems and slopes in badlands at Perth Amboy, New Jersey. Geological Society of America Bulletin. 67(5), 597-646. https://doi.org/10.1130/0016-7606(1956)67[597:EODSAS]2.0.CO;2 
Research, Society and Development, v. 11, n. 2, e42811225698, 2022

(CC BY 4.0) | ISSN 2525-3409 | DOI: http://dx.doi.org/10.33448/rsd-v11i2.25698

Schumm, S. A. (1963). Sinuosity of alluvial rivers on the great plains. Geological Society of America Bulletin, 74(9), 1089-1100. https://doi.org/10.1130/0016-7606(1963)74[1089:SOAROT]2.0.CO;2

Simas, A. S., Tataje, D. A. R., \& Filho, E. Z. (2014). Pools and rapids as spawning and nursery areas for fish in a river stretch without floodplains. Neotropical Ichthyology, 12(03), 611-622. https://doi.org/10.1590/1982-0224-20130116

Sistema de Referência Geocêntrico para as Américas (SIRGAS) (2000). https://sirgas.ipgh.org/

Stipp, N. A. F., Campos, R. A., \& Caviglione, J. H. (2010). Análise morfométrica da bacia hidrográfica do rio Taquara - Uma contribuição para o estudo das ciências ambientais. Portal da Cartografia, 3(1), 105-124. https://www.uel.br/revistas/uel/index.php/portalcartografia/article/view/8929

Strahler, A. N. (1952). Dynamic basis of geomorphology. Geological Society of America. Bulletin, 63(9), 923-938. https://doi.org/10.1130/00167606(1952)63[923:DBOG]2.0.CO;2

Tarboton, D. (2015). TauDEM Version 5. Hydrology Research Group, Utah State University. https://hydrology.usu.edu/taudem/taudem5/downloads.html

Tonello, K. C., Dias, H. C. T., Souza, A. L., Ribeiro, C. A. A. S., \& Leite, F. P. (2006). Morfometria da bacia hidrográfica da Cachoeira Das Pombas, Guanhães - MG. Revista Árvore, 30(5), 849-857. https://doi.org/10.1590/S0100-67622006000500019

Tucci, C. E. M. (Org.) (2001). Hidrologia: Ciência e aplicação. Ed. da UFRGS/ABRH.

United States Geological Survey - USGS (2011). Aster global DEM. ASTER GDEM is a product of METI and NASA. https://lpdaac.usgs.gov/news/metiand-nasa-release-version-2-aster-global-dem/

Villela, S.M., \& Mattos, A. (1975). Hidrologia aplicada. McGraw Hill do Brasil.

Wallace, A. R. (1876). The geographical distribution of animals. V.1. Harper \& Brothers, Publishers. http://www.obrasraras.usp.br/jspui/handle/123456789/1082

Tundisi, J. G. (2003). Água no século XXI: enfrentando a escassez. RiMa/IIE. 